\title{
Principles of Acquaintance
}

\author{
Jessica Pepp, Uppsala University
}

This is a draft of a chapter prepared for publication in New Essays on Acquaintance, edited by Thomas Raleigh and Jonathan Knowles, Oxford University Press (forthcoming).

The thesis that in order to genuinely think about a particular object one must be (in some sense) acquainted with that object has been thoroughly explored since it was put forward by Bertrand Russell. Recently, the thesis has come in for mounting criticism. The aim of this paper is to point out that neither the exploration nor the criticism have been sensitive to the fact that the thesis can be interpreted in two different ways, yielding two different principles of acquaintance. One principle uses the notion of content in distinguishing genuine thinkingabout things from a merely derivative kind of thinking-about things. The other principle is quiet about content, focusing instead on a distinction between satisfactional and nonsatisfactional means of bringing things into thought. Most work has focused on the first, content-based principle of acquaintance. But criticisms of this principle do not apply straightforwardly to the non-content-based principle. I shall argue that the latter principle merits independent assessment as part of the broader effort to account for genuine thinking about particular objects. In the final section of the paper, I will sketch a roadmap for this assessment.

Suppose Jane is thinking about tigers - she is thinking that they are beautiful and scary. Greta is a tiger whom Jane has never encountered. Is Jane thinking about Greta? There is a sense in which she is. Her thought applies to Greta. But she is thinking about Greta only insofar as she 
is thinking about tigers and Greta is a tiger. Greta is not in her thought in any way over and above this. Now suppose Jane is thinking that the biggest of all tigers must be beautiful and scary, and suppose Greta is in fact the biggest of all tigers. Is Jane thinking about Greta? Again, there is a sense in which she is: her thought applies to Greta; Greta is the (unique) satisfier of the condition (being the biggest tiger) that Jane is thinking of. But again, Jane is thinking about Greta only insofar as she is thinking about being the biggest of all tigers and Greta is the biggest of all tigers. Greta is not in her thought in any way over and above this.

In general, we can distinguish a loose sense in which thoughts are about things to which they apply from a more substantial notion of a thing's independently being in thought. What can we say about this more substantial notion? What is it for a thing to be in thought (and not merely to be thought about, in the looser sense)? (In what follows I will sometimes use "being-in-thought" to refer to the phenomenon of genuinely being in thought, as distinguished from being thought about, in the looser sense.)

Bertrand Russell gave a partial answer to this question: for a thing to be in thought, the thinker must be acquainted with the thing. This is now known as Russell's "Principle of Acquaintance." I take Russell's basic statement of this principle to be the following:

\section{Russell's Basic Principle of Acquaintance}

"All thinking has to start from acquaintance; but it succeeds in thinking about many things with which we have no acquaintance.” $(1905,874)$

The principle is the part in boldface. The continuation of the sentence serves to contrast the substantial notion of being-in-thought that is claimed to require acquaintance, from the looser 
notion of being thought about that includes satisfying a condition that is in thought. This looser, satisfactional way of being thought about requires a "start" in things that are thought about in the more substantial way. Russell's Basic Principle of Acquaintance says that for a thing to be in thought in this starting, non-satisfactional way, the thinker must be acquainted with it.

Russell also endorsed the following principle of acquaintance:

\section{Russell's Propositional Principle of Acquaintance}

"Every proposition which we can understand must be composed wholly of constituents with which we are acquainted." $(1910 / 11,117)$

For Russell, this principle is another way of stating his Basic Principle of Acquaintance, since he held that being in thought in the more substantial, non-satisfactional sense is necessary and sufficient for being a constituent of a proposition that is grasped in thought. But at least on the surface, these are different principles of acquaintance. Russell's Propositional Principle of Acquaintance puts an acquaintance requirement on being a constituent of a proposition grasped in thought. Russell's Basic Principle of Acquaintance, by contrast, puts an acquaintance requirement on being at the non-satisfactional "start" of thinking about.

These principles of acquaintance are supposed to be informative about how things get into thought. Their point is not simply that grasping propositions happens to require acquaintance with the constituents of those propositions, or that it happens to be the case that only things with which we are acquainted can be in thought non-satisfactionally. Rather, the idea behind the principles is that acquaintance is required because a thing's being thought about non- 
satisfactionally or being a constituent of a proposition grasped in thought derives from the thinker's being acquainted with it. The strongest form of this idea is that a thing's being-inthought (understood in either way) just is the thinker's acquaintance with the thing.

This sounds wrong if being-in-thought is considered as an occurrent phenomenon while acquaintance is considered as a non-occurrent phenomenon. For, as Russell noted, one might at a given time be acquainted with many things that are not, in an occurrent way, in one's thought at that time. $(1910 / 11,109)$ However, acquaintance can also be considered as an occurrent phenomenon. Russell described occurrent acquaintance with a thing as being directly aware of or being presented with the thing. So, we can characterize the idea behind the principles as follows: a thing's being-in-thought derives from its being presented to the thinker — from an episode of occurrent acquaintance with the thing.

Of course, these principles are not informative until "acquaintance" is defined. Philosophers from Russell onward have had different ideas about what counts as acquaintance. A common thread is that perception is critical, at least with respect to acquaintance with particulars. Russell thought that the particulars with which we are acquainted are our own sense data because, as a sense datum theorist, he thought that these are what we really perceive. Current writers tend to go in the other direction, extending acquaintance to cover not only perception of external objects, but also awareness of them deriving from perception, such as perceptionbased memory of them, uptake from others' linguistic reference to them (where this linguistic 
reference is ultimately based on someone's perception of the object), or memory of them based on earlier linguistic uptake. ${ }^{3}$ Robin Jeshion gives a useful formulation of a liberal version of this extension:

Jeshion's "Standard-Standard on Acquaintance":

"One can be acquainted with an object $\mathrm{O}$ only by perception, memory, and communication chains." $(2010,109)$

Jeshion's Standard-Standard suggests the following requirement for occurrent acquaintance: To be occurrently acquainted with an object one must either be: (i) perceiving the object, (ii) being referred to the object ${ }^{4}$ via a communication chain originating in someone's perception of the object, or (iii) remembering the object (with the memory deriving either from one's past perceptions of the object or from one's past uptake of the object via language).

This requirement may raise concerns because it seems to exclude abstract objects from being objects of occurrent acquaintance, given that (as many believe) they cannot be perceived. If so, then the truth of either acquaintance principle would exclude abstract objects from being in thought. It is a substantive question whether abstract objects can be perceived, and it depends to some degree on how one understands perception. Charles Parsons (1980) and Penelope Maddy (1980), for instance, develop accounts of mathematical intuition that treats the intuiting of certain abstract mathematical objects as, in effect, a variety of perception. Treatment of this matter is beyond the scope of the present paper. I will follow the fairly

\footnotetext{
${ }^{3}$ Dickie (2016) calls this the "extended acquaintance tradition." Hawthorne and Manley (2012) call it "causal acquaintance."

${ }^{4}$ Here I use "being referred to the object" in roughly the same way as Bach (2008): in understanding a use of a word to refer to an object, one is referred to that object.
} 
standard practice in current discussions of acquaintance requirements, and restrict my discussion to concrete objects. ${ }^{5}$

In addition to adopting something like the Standard-Standard on acquaintance, current discussions focus on acquaintance requirements that are more in the vein of Russell's Propositional Principle of Acquaintance than his Basic Principle of Acquaintance. Current writers typically are committed neither to the wholly propositional nature of thought nor to Russell's particular metaphysics of propositions, according to which propositions are abstract objects having worldly objects and properties as literal constituents. A more general descendent of the Propositional Principle of Acquaintance, which also takes account of the refinements just discussed, can be stated as follows:

\section{Content Principle of Acquaintance (CPA):}

For a concrete object to figure in the content of one's occurrent thought, one must be occurrently acquainted with the object — that is, one must be perceiving the object, being referred to it via a perception-based linguistic communication chain, or remembering it via one of those two kinds of earlier experience.

An object's figuring in the content of thought is often described as the thought being a "singular thought" about that object. Singular thought and the CPA have been the focus for recent investigations of the role for acquaintance in accounting for the substantial kind of being-in-thought. CPA has been the subject of much criticism. Some have even suggested that

\footnotetext{
${ }^{5}$ If abstract objects cannot be perceived, then rejection of a Standard-Standard acquaintance requirement on concrete objects being-in-thought might be a positive development, as it would allow a unified treatment of being-in-thought across both abstract and concrete objects. (Jeshion 2002, 57 suggests this.) Nonetheless, if an acquaintance requirement is defensible with respect to concrete objects, this cannot be ignored simply in the interest of ensuring a unified account.
} 
problems with CPA show that the notion of acquaintance "is a dispensable relic of a bygone era in the philosophy of language and mind." (Hawthorne and Manley 2012, 25) In section 4, I will argue that however powerful the evidence against CPA may be, a claim like this is at best premature. The reason is that the Basic Principle of Acquaintance affords another potentially important role for the putative relic of acquaintance. It needs to be assessed separately from CPA. Nonetheless, the kinds of problems that arise for CPA are instructive, both in making the case that BPA deserves separate attention, and in making a start on evaluating BPA. Given this, I will briefly review the case against CPA in the next section.

Criticisms of CPA can be divided into two categories: arguments by counterexample and arguments by failure of motivation. The counterexample-based arguments adduce cases in which, intuitively, an object figures in the content of thought (the thought is a "singular thought" about the object), but in which the thinker has no acquaintance (in the extended Standard-Standard sense) with the object. The arguments by failure of motivation aim to show that traditional explanatory roles for acquaintance requirements on singular thought can be filled in other ways, or that acquaintance requirements do not in fact play those roles.

Counterexamples to CPA need to evoke the intuition that an object is figuring in the content of occurrent thought, although the thinker is not perceiving the object, being referred to it in language, or remembering it via one of those two kinds of earlier experience. The first part of this intuition concerns a theoretical status: an object's figuring in the content of thought, or 
the thought's being singular with respect to the thing. Critics of CPA acknowledge that one's intuitions about this matter will be shaped by one's theory of singular thought. ${ }^{6}$ Their general strategy, however, is to use a rich diet of examples to issue the challenge: if you are going to draw a distinction between thought whose content is singular as opposed to general with respect to an object, do you not want at least some of these cases to fall on the singular side? If you do, and you endorse CPA, you have a problem, because in none of these cases is the thinker perceiving the object, being referred linguistically to the object via a perception-based communication chain, or remembering the object through either of these kinds of earlier experience.

The kinds of examples used to issue this challenge include inference cases, future existents cases, linguistic cases, and map cases. First, there seem to be cases of thinking singularly about a thing whose existence one infers, though one has no perception-based link to it. For instance, a car mechanic might infer from the appearance of a car that it has an engine which has not been well treated, and think that that engine is destroyed. Second, there seem to be cases of thinking singularly about a thing that one has reason to believe will come to exist, despite there being no possibility of a perception-based link, as the thing does not yet exist. For instance, one might intend to have a child, and think that that child will have light hair. Third, there seem to be cases of thinking singularly about a thing using a name or indexical expression, despite having no perception-based link to it. For instance, one might use the word "I" to think of oneself in a way that is (arguably) not based on any perception of one by oneself or by anyone else. Or one might use a name like "Mitochondrial Eve," which was introduced without any perceptual link to the individual it names, ${ }^{7}$ to think of a particular

\footnotetext{
${ }^{6}$ See, for instance, Jeshion (2010, 112-13) and Hawthorne and Manley (2012, 3-4).

${ }^{7}$ In human genetics, "Mitochondrial Eve" is the name given to the most recent matrilineal common ancestor of all currently living humans.
} 
individual. Fourth, there seem to be cases of thinking singularly about a location using a map (physical or mental), despite having no extended perceptual link to that location. For instance, a cartographer might map the coastline of an island and use it to think that that (spatially identified) inland location, which neither he nor anyone he is in contact with has ever perceived, is windy. ${ }^{8}$

Putative counterexamples such as these may cast doubt on CPA. But one can also ask what reason there is to endorse $\mathrm{CPA}$ in the first place. A cluster of traditional motivations relate to what I will call the "focus-shifting manoeuvre." It seems that if Jane is able to think about there being a biggest of all tigers, then nothing stops her from shifting her cognitive focus from this condition to its satisfier. She might do this by introducing a name for whoever is the biggest tiger and going on to think with that name, or by thinking in a way that she might express as concerning "that animal — the one who is in fact the biggest tiger." If Jane can shift her cognitive focus in this way, then it is not clear why the content of her thought should not also shift. Why should it not be that Jane goes from thinking that among the tigers the one who is biggest is beautiful and scary, to thinking that that tiger - the biggest one - is beautiful and scary?

The focus-shifting manoeuvre has suggested to some that "semantic instrumentalism"10 is true. This is the view that if a thinker can entertain a content containing a condition she believes satisfied, and if she can introduce a name (or other term) whose reference she stipulates to be fixed by that condition, then she can use that name to entertain a content

\footnotetext{
${ }^{8}$ These examples are drawn from or inspired by the discussions in Jeshion (2010) and Hawthorne and Manley (2012). As Hawthorne and Manley note, similar examples have been discussed by a range of other philosophers, notably Sosa (1970), Jeshion (2002), McGinn (1981), and Sutton (2001).

${ }^{9}$ This would be a mental equivalent of introducing a Kaplanian "dthat" term. (Kaplan 1989)

10 "Semantic instrumentalism" is Jeshion's name for the view, which is typically traced to Kaplan (1989), and is also attributed to Harman (1977) and Borg (2007).
} 
containing the satisfier of that condition. But most theorists reject semantic instrumentalism, presumably because it lets things into "singular thought" too easily. This is one motivation for positing substantive requirements on figuring in the content of thought, such as CPA. ${ }^{11}$

Another problem that derives from the focus-shifting manoeuvre is that the manoeuvre seems to allow us to gain new knowledge too easily. If Jane knows that among all the tigers, one is biggest, why can she not shift her focus to that individual—Greta—and come to know something she did not know before: namely, that Greta is the biggest tiger?

CPA seems to offer an explanation. Jane does not come to know anything new by this procedure because she does not come to entertain a new content that attributes being the biggest tiger to the individual who is in fact the biggest tiger, Greta. For her thought to have this content, the thought would have to be derived from acquaintance with Greta. But Jane's shift in cognitive focus has done nothing to remedy her lack of acquaintance with Greta.

Hawthorne and Manley challenge this explanation by imagining similar procedures which $d o$ remedy Jane's lack of acquaintance with Greta. Suppose Jane has a magic arm that will reach out and allow her to touch whoever is the biggest tiger. Jane can then name this individual "Biggie." This naming, and Jane's subsequent thought using the name, do derive from Jane's (tactile) perception-based acquaintance with Greta. Alternatively, suppose Jane orders a magical fairy to go and find the biggest tiger, become perceptually acquainted with that individual, and name her "Biggie." When the fairy returns and tells Jane "Biggie is the biggest tiger," Jane is referred via a perception-based linguistic communication chain to Greta. Despite all this, Hawthorne and Manley think, we should be no happier attributing new

\footnotetext{
${ }^{11}$ A different supplementary requirement is Jeshion's (2010) requirement that anything figuring in the content of thought be thought about using a mental file.
} 
knowledge to Jane in these cases than in a case where she simply performs the focus-shifting manoeuvre. And if Jane's gaining acquaintance via these procedures does not create new knowledge, then Jane's not gaining acquaintance via the original procedure does not explain why the original procedure does not create new knowledge.

A similar point could be made about using CPA to avoid semantic instrumentalism. If using the magic arm or the magic fairy would still be too easy a way to have singular thoughts about things, then the problem with semantic instrumentalism is not that the semantic version of the focus-shifting manoeuvre does not acquaint the thinker with the satisfier of the condition. For even if it did, our intuition would still be that singular thought is not so easily obtained.

\section{4}

With this brief review I have provided only a partial sketch of the case against CPA, and I have made no evaluation of it. This is because my interest is not in rejecting or defending CPA but in pointing out that however strong the case against CPA may be, it is not the whole story of whether acquaintance requirements have a place in a right account of being-inthought. Although Russell treated his version of CPA as another way of expressing the Basic Principle of Acquaintance, they are different principles. If CPA is false, this does not entail that the Basic Principle of Acquaintance is false.

Here is a version of Russell's Basic Principle of Acquaintance, that "all thinking has to start from acquaintance," revised and restricted in parallel with the statement of CPA in section B. 


\section{Basic Principle of Acquaintance (BPA):}

For a concrete object to be in one's occurrent thought in non-satisfactional way, one must be occurrently acquainted with the object — that is, one must be perceiving the object, being referred to it via a perception-based linguistic communication chain, or remembering it via one of those two kinds of earlier experience.

For BPA to entail CPA, figuring in the content of thought would have to entail being thought about in a non-satisfactional way. For CPA to entail BPA, being thought about in a nonsatisfactional way would have to entail figuring in the content of thought. It is not obvious that either of these is the case. Take the car mechanic case mentioned above: in the mechanic's thought that that engine is destroyed, it is supposed to be the engine that figures in the content of the thought, even though, at least arguably, the engine is thought about only by satisfying a condition that is in thought, such as being the engine in that car. If this is right, then figuring in the content of thought does not entail being thought about in a nonsatisfactional way, hence BPA does not entail CPA.

It also seems at least possible that, although the car is (let us suppose) thought about in a nonsatisfactional way, it does not figure in the content of thought. (The thought is about the engine, not the car.) Of course, this depends on the details of one's theory of thought contents. But if it is coherent, then it is not obvious that being thought about in a non-satisfactional way entails figuring in the content of thought. Thus it is coherent to endorse CPA but reject BPA.

The important point for my purposes, though, is that BPA does not entail CPA; hence if CPA is false, this does not entail that BPA is false. Furthermore, the question with which I began the paper-what can we say about being-in-thought in the substantial sense that contrasts with 
satisfying a condition in thought?-is of interest even if one does not restate the question in terms of content.

Maintaining non-satisfactional aboutness as the important mark of genuine being-in-thought, instead of focusing on singular content, has some advantages. One is that no problem of semantic instrumentalism arises. One can think about something via a condition that the thing satisfies, and one can introduce a name whose reference one stipulates to be fixed by that condition. One can go on to use that name in thinking about the thing. None of this changes the fact that one is thinking about the thing by means of its satisfying a condition that is in thought. Even if one goes on to think about the thing using the name without keeping the condition in occurrent thought, one's previous occurrent thought about the condition is still part of the means by which one is now thinking about the thing. No semantic manoeuvre can kick away the essential role for the condition in making one's thought be about the thing. The only way for this to change is for one to acquire a different, non-satisfactional way of thinking about the thing.

Another advantage of focusing on non-satisfactional aboutness is that it may present a different way to deal with the problem of too-easy knowledge. Once we think of knowing something as knowing a content, we are faced with the problem that the focus-shifting manoeuvre seems to allow one to entertain a content that one is thereby (in virtue of having used that very procedure) in a position to know. If CPA and related substantive requirements on figuring in singular contents turn out to be unmotivated, the question remains of why knowledge cannot be gained by the focus-shifting procedure. Hawthorne and Manley's suggestion seems to be that new knowledge can be gained in this way, it is just that the knowledge is not "interesting" or "momentous" $(2012,67)$. This is not altogether satisfying. 
Suppose we instead treat knowledge that (e.g.) Greta is the biggest tiger as knowledge of the fact of Greta's being the biggest tiger. ${ }^{12}$ One way to conceive of knowing a fact is as having that fact in thought. Having a fact in thought is different from having (in the simple case) an object in thought and a property in thought, and doing a cognitive operation to ascribe the property to the object. Even if the ascription happens to be true, this is not enough for having the fact (that the object has the property) in thought. This is analogous to the intuition that having tigers in thought and bigness in thought, and doing a cognitive operation to form the condition of being the biggest tiger, is not sufficient for having Greta in thought.

I would then suggest that in the same way that Jane thinks of Greta only by thinking with the condition the biggest of all tigers, she thinks of (the fact of) Greta's being the biggest of all tigers only by thinking with the condition someone's being the biggest of all tigers. ${ }^{13}$ The former condition is satisfied by Greta; the latter is satisfied by the fact of Greta's being the biggest of all tigers. Thus, neither Greta nor the fact of Greta's being the biggest of all tigers are genuinely in Jane's thought after she uses the focus-shifting procedure. Accordingly, no new knowledge of facts is gained.

One might worry that this approach to the problem still leaves it open that in the case where Jane employs the magic fairy to gain acquaintance with the satisfier of the condition, she does gain new knowledge. For it seems that when the fairy says, "Biggie is the biggest tiger," this

\footnotetext{
${ }^{12}$ Admittedly, treating knowledge that such-and-such as knowledge of worldly facts is a minority approach. (See Kratzer 2002 for a relatively recent defense, though she does not conceive of knowing a fact in the way I suggest below.) What follows in the text should only be taken as suggestive of a different sort of approach to the problem of too-easy knowledge that does not involve a focus on content.

${ }^{13}$ Note that one might also think of Greta's being the biggest of all tigers satisfactionally in the following way. Suppose one thinks of Greta (non-satisfactionally, we may suppose) and, because of her large size, assumes that she is the biggest of all tigers. One thus forms a condition in thought, (the fact of) Greta's being the biggest of all tigers, which is in fact satisfied by (the fact of) Greta's being the biggest of all tigers. But this fact is not in thought in any way over and above satisfying this condition.
} 
enables Jane to think about the fact of Biggie's (Greta's) being the biggest tiger in a way that is arguably non-satisfactional. ${ }^{14}$ This is a plausible upshot, but I do not think it is a problem for the approach. For the approach offers an explanation of why (despite potentially countervailing intuitions) the fairy procedure might create new knowledge of facts while the initial focus-shifting procedure does not. The explanation is that the fairy procedure gives one a non-satisfactional way of thinking of certain facts, which is, on this approach, what it is to know them. And while one can build the case (as Hawthorne and Manley do with the fairy case) so that this knowledge is of little instrumental significance, the knowledge is significant in other ways.

This is illustrated by an example that Jeshion (2010) discusses, of an adoptee who yearns to meet his biological mother. ${ }^{15}$ The adoptee knows that he has a unique biological mother, so he can use the focus-shifting procedure to think about the fact that she is his biological mother. But he thinks about this fact only by means of thinking of someone's being my unique biological mother. ${ }^{16}$ The man goes on this way for many years, marvelling at the fact that he does have a mother, and pondering over what she might be like. Now let us add to Jeshion's example that, at long last, the man saves up enough money to hire a private detective to go out and locate his biological mother. The detective returns and tells the man, "I found her. She is your mother, all right." It seems to me that even if nothing further follows from this (maybe the detective suddenly drops dead and none of his records can be located), something has

\footnotetext{
${ }^{14}$ Notice that the magic arm case does not obviously have the same result. It may be that Jane thinks about Biggie/Greta in a non-satisfactional way through touching Greta with the hand of her magic arm, but it is less clear that she thinks about the fact of Greta's being the biggest tiger in a non-satisfactional way. More plausibly, she thinks about her touching the biggest tiger in a non-satisfactional way, and thinks about the fact that Greta is the biggest tiger only by means of thinking with the condition, this thing's being the biggest tiger, which the latter fact satisfies. By contrast, she can now think of the fact of Greta's being solid, or having other tactile features, in a non-satisfactional way.

${ }^{15}$ Jeshion adapts the example from one used in Velleman (2008).

${ }^{16}$ Jeshion uses this case to evoke the intuition that the adoptee is able to entertain singular contents about his mother (presumably, despite the fact that his means of thinking of her is satisfactional). Jeshion does not discuss the case in terms of facts or ways of thinking about them.
} 
changed. Although this change does not open up new possibilities for the man to act, it is nonetheless interesting and momentous. The fact of a particular person's being his mother has come into the man's thought in a new way. He is no longer thinking of this fact by thinking with the condition, someone's being my unique biological mother. Rather, another person has encountered this fact and reported it to him. He thus gains knowledge of that fact that he did not have before.

These reflections on the problem of too-easy knowledge are far from conclusive. They are only intended to give the flavour of an approach one might take if one maintains nonsatisfactional aboutness, rather than singular content, as the primary mark of being-in-thought. When singular content is adopted as the primary mark of being-in-thought, problems like semantic instrumentalism and too-easy knowledge invite theorists to place substantive requirements on content-inclusion, such as CPA. By contrast, when non-satisfactional aboutness is the focus, semantic instrumentalism does not arise, and other avenues are available for addressing the problem of too-easy knowledge. Since these problems connect to basic commitments about being-in-thought, this provides some inducement to focus on nonsatisfactional aboutness as the mark of being-in-thought, and to assess BPA rather than-or at least as well as - CPA in the effort to give an account of being-in-thought. In the final part of the paper, I will take a first step in this direction by outlining the initial plausibility of BPA and the kinds of challenges against which it should be tested. 
If concrete objects can be thought about in a non-satisfactional way, what would that way be? An answer that immediately presents itself is that we can perceive concrete objects, or get told about them by others who have perceived them, and we can remember them through these experiences. In other words, we think about them by means of our acquaintance (in the Standard-Standard sense) with them. Acquaintance with concrete objects seems to be a paradigm means of thinking about them in a non-satisfactional way. ${ }^{17}$ This does not imply that all non-satisfactional thinking about concrete objects is via acquaintance. But it provides some initial motivation for BPA and sets the task of challenging BPA by identifying ways of thinking about concrete objects that are not via acquaintance.

One place to look is among the putative counterexamples to CPA mentioned above. These are examples in which it is supposed to be intuitive that the content of thought is singular with respect to some object, although the thought is not derived from the thinker's acquaintance with that object. If it is also intuitive in some of these cases that the relevant object is thought about in a non-satisfactional way, then these cases could serve as counterexamples to BPA.

Inference cases, future existents cases, and maps cases do not clearly fit this bill. As described, the cases do not elicit the intuition that the things are thought about nonsatisfactionally. Indeed, it seems plausible (for example) that the car mechanic thinks of a particular car engine by means of thinking with the condition the engine of this car. It seems plausible that an individual contemplating his future thinks of some particular future child of

\footnotetext{
${ }^{17}$ Some hold that perceiving concrete objects only lets us think about them in a satisfactional way (e.g., Searle 1983). One who had such a view might reject BPA, if (but only if) she also held that there are other, nonperception-based non-satisfactional ways of thinking about concrete objects. I discuss some possibilities in this vein below.
} 
his by means of thinking of the condition the (first/only, etc.) child that I will have. It seems plausible that the cartographer thinks of a particular area on the island he charts by means of thinking with the condition the area that is such-and-such distance in such-and-such direction from this point on this coastline.

Cases of thinking of things using linguistic devices seem more promising as potential counterexamples to BPA. A thinker might understand sentences like "I am hungry" or "Mitochondrial Eve lived over 100,000 years ago," and thereby think of herself or of a certain human being, but not in virtue of thinking of, or with, conditions that she or that human being satisfies. (She might not know the reference-fixing condition associated with the name "Mitochondrial Eve," despite having picked up the name in biology class.) Rather, it might be suggested, the linguistic conventions governing the expressions determine referents for uses of those expressions. If she can refer to those things, and understand these claims about them, it is not clear why we should not also allow that she is thinking of those things.

Some have questioned the view that being able to refer in language to a thing, and to understand talk about it, is sufficient for being able to think about it. ${ }^{18}$ Even if we accept this (as I am inclined to), we may question whether the semantic operation of introducing a name like "Mitochondrial Eve" via a reference-fixing description enables anyone to think about the satisfier of that description in a non-satisfactional way. If such semantic manoeuvres do not have this power (as suggested in section 4), then a speaker who picks up this name from another speaker acquires (at most) the ability to think about Mitochondrial Eve in a satisfactional way, albeit by means of the source speaker's thinking with the condition the matrilineal most recent common ancestor of all currently living humans.

\footnotetext{
${ }^{18}$ Most notably, Gareth Evans (1982, chapter 11). See also McGinn (1981).
} 
In addition, there is a question about the order of determination. When thinking with words, does one think of things in virtue of thinking with words governed by linguistic conventions that (perhaps relative to context) determine those things as referents? Or does one refer using those words to those things in virtue of the fact that one's use of the words results from thinking about those things? I think there is reason to favour the latter view. ${ }^{19}$ Further, it is not clear what it takes for a use of a word to be governed by a reference-determining convention. ${ }^{20}$ Such considerations suggest that it is difficult to make the case that linguistic conventions can make things be in thought.

Nonetheless, the example of indexical expressions in particular points to a stronger challenge to BPA. Independent of conventional linguistic expressions, we seem to have a special, "firstpersonal" way of thinking of persons, places, and times. We think of persons as $I$, places as here, and times as now. (By which I do not imply that we have to use those words, or any words.) At least to many philosophers, this first-personal way of thinking of things has seemed to be independent of any perception, memory, or linguistic reference to the things thought of. But it also seems clear that at least some things thought of in this way must be in thought in a non-satisfactional way. For if I think of (for instance) my present location in a satisfactional way, by means of thinking with the condition, being the place where I am now, then the question arises of how I am thinking of myself and of the present time, which figure in that condition. If it is by thinking with the condition, being the person who is here now, a circularity immediately emerges. Either first-person thought about myself, my time, and my

\footnotetext{
${ }^{19}$ I make the case for this in Pepp (forthcoming).

${ }^{20}$ The difficulty of making out what it is for a convention to be "in force" for a use of a word has been emphasized by Pagin (1987) and Glüer and Pagin (1999). I develop this difficulty with respect to the reference of words, as used, specifically in Pepp (forthcoming).
} 
location comes as a unit, ${ }^{21}$ or some of these are thought about in a non-satisfactional way while others are thought about satisfactionally. Either way, there is some first person thinking that is non-satisfactional. If this is right, and if some of the things thought of in this way are concrete objects, then BPA is false.

For the sake of argument, I will accept that some of the things thought of in this way (for example, people) are concrete objects. Then the main point I want to make here is that BPA depends on the correctness of a broadly perceptual account of what makes first-person thought be about things. This is a substantial challenge to BPA, as such accounts are widely believed to run afoul of a central desideratum. The desideratum is that an account of what makes first person thought be about things should entail that an individual's first person thought — be it I-thought, now-thought, or here-thought — cannot fail to be about that person, or the time or place of her thought. Yet, if things are brought into first-person thought via perception, it is not clear how this desideratum could be guaranteed. If one lacks perceptual contact with oneself or one's spatiotemporal location, one's first-person thought could not be about these things, violating the desideratum. ${ }^{22}$ Similarly, if one's perceptual contact is with something other than oneself or one's spatiotemporal location, one's first-person thought could not be about these things, again violating the desideratum. ${ }^{23}$

Evaluation of this challenge to BPA requires (i) assessing whether it is really a desideratum for an account of first-person being-in-thought that it should entail this kind of stickiness to the thinker, and (ii) assessing whether a perceptual account really violates this desideratum. These are big questions with a literature of their own, into which I will not enter here. ${ }^{24}$ For

\footnotetext{
${ }^{21}$ As suggested by Evans 1982, 153.

${ }^{22}$ Anscombe $(1975,58)$.

${ }^{23}$ See Campbell (1994) and O’Brien (2007, chapter 3).

${ }^{24}$ See, for instance, Campbell (1994), O’Brien (2007) and (1995), Morgan (2015), Peacocke (2008, 2014).
} 
purposes of the present paper, I am content to tie the truth of BPA to these questions. They are key questions to answer in the effort to understand whether acquaintance, in the broad perceptual sense that I have been using that term, is essential to genuine being-in-thought for concrete objects.

Another source of counterexamples might be what David Kaplan (2012) calls "evidence cases." In these cases, one thinks about a thing by means of some evidence one has of it, but the condition one uses to think about the thing is not in fact satisfied by the thing. Additionally, it is supposed to be intuitive about these cases that one has no perception-based acquaintance with the thing. Kaplan describes a case in which his computer appears to have been stolen. He goes in search of what he would describe as "the person who stole my computer," and finds the person he was looking for. However, it turns out that "unbeknown to either of us, he has an ownership right in the computer, so it wasn't actually a theft or (on the basis of some even more fantastic scenario) it isn't actually a computer." $(2012,144)$ It seems that all along Kaplan was thinking of that person (plotting revenge upon him, wondering how he could be so selfish, and so on) though not in virtue of the person satisfying the condition that Kaplan used to think about him, and not by means of having perceived the person, or having been told about the person by anyone who has perceived him. Thus, this appears to be a case of non-satisfactional but non-acquaintance-based thinking about the person, and so a counterexample to BPA.

However, both the "non-satisfactional" and the "non-acquaintance-based" parts of this judgment can be questioned. One might argue that in such cases there is always a "back-up" condition in thought that is satisfied by the thing thought about, and that this is really the means by which the thinker thinks about the thing. For instance, it might be claimed that 
Kaplan is also thinking with the condition the person or persons that removed the thing that used to sit in that spot on my desk, and the person he is thinking about does satisfy that condition. $^{25}$

One might also question whether these are in fact cases in which the thinker does not perceive the object. In the case that Kaplan discusses, Kaplan's thinking of the computer-taker is not derived from his (or anyone else's) seeing, hearing, or touching that person. But this is not decisive on the question of whether his thinking is derived from his perceiving that person. For he might be perceiving that person indirectly, much as he might perceive him by perceiving footage from a closed-circuit television monitor that caught the taker in the act, or through a still image captured from such footage. The crime scene might similarly be a kind of record through which one can, indirectly, perceive that person. The question of whether there is genuine perception through photograph and video images remains a live one in philosophical aesthetics. ${ }^{26}$ Even if this debate were settled in favour of there being such indirect perception, it is a further question whether there is also perception through other sorts of records or traces.

These two lines of questioning need to be explored more fully to assess (i) whether thinking about things via evidence relies on those things satisfying conditions that are in thought, even if they fail to satisfy some other conditions that are in thought, and (ii) whether evidence provides an indirect perceptual link to things. If either of these claims proves defensible, then

\footnotetext{
${ }^{25}$ For an extended discussion of these kinds of cases and this kind of response to them, see Dickie (2016, chapter 6). Dickie argues that in such cases the objects are thought about neither by condition satisfaction (even of backup conditions) nor by acquaintance.

${ }^{26}$ The classic discussion is Walton (1984), where perception through photographs is defended as genuine perception. Criticisms and defences of Walton's position include Currie (1991), Carroll (1996), Friday (1996), Walton (1997), Lopes (2003), Cohen and Meskin (2004), and Nanay (2010).
} 
evidence cases are not a clear counterexample to BPA. This is an additional important line of inquiry in assessing BPA.

\section{Conclusion}

The purpose of advancing, challenging, and defending principles of acquaintance is to investigate the broader question of what it is for things genuinely to be in our thought. Much of the effort to do this since Russell has focused on the Content Principle of Acquaintance. This principle adopts being in, or figuring in, content as the mark of genuinely being in thought. There is no entailment from the Basic Principle of Acquaintance, which focuses on the difference between satisfactional and non-satisfactional thinking about things, to the Content Principle of Acquaintance. Thus, even if criticisms of CPA are decisive, they do not straightforwardly apply to BPA. Further, there are problems associated with using content to divide genuine from derivative being-in-thought. Taken together, these considerations favour at least taking seriously BPA as a route to shedding light on genuine being-in-thought. I have suggested that two key lines of investigation in evaluating BPA are (i) the question of whether a perceptual account of first-person thinking is viable, and (ii) the question of whether Kaplan's and Dickie's “evidence cases” are really cases of both non-satisfactional and nonacquaintance-based thinking of things. These questions are of interest in their own right, and gain additional interest from their role in evaluating BPA. They should be approached with the distinction between CPA and BPA, and the choice of whether to use the notion of content in conceiving of genuine being-in-thought, firmly in mind. 


\section{References}

Anscombe, Elizabeth, 1975. 'The first person'. In Mind and Language, edited by Samuel D. Guttenplan, 45-65. Oxford: Oxford University Press.

Bach, Kent, 2008. 'On Referring and Not Referring'. In Reference: Interdisciplinary Perspectives, edited by J. Gundel and N. Hedberg, 13-59. Oxford: Oxford University Press.

Borg, Emma. 2007. Minimal Semantics. Oxford: Oxford University Press.

Campbell, John. 1994. Past, Space, and Self. Cambridge, USA: MIT Press.

Carroll, Noel. 1996. Theorizing the Moving Image. Cambridge: Cambridge University Press.

Cohen, Jonathan and Aaron Meskin. 2004. 'On the epistemic value of photographs'. Journal of Aesthetics and Art Criticism (62)(2): 197-210.

Currie, Gregory, 1991. 'Photography, painting, and perception'. The Journal of Aesthetics and Art Criticism (49)(1): 23-29.

Dickie, Imogen. 2016. Fixing Reference. Oxford: Oxford University Press.

Evans, Gareth. 1982. The Varieties of Reference. Edited by John McDowell, Oxford: Oxford University Press.

Friday, Jonathan, 1996. 'Transparency and the Photographic Image'. British Journal of Aesthetics (36)(1): 30-42.

Glüer, Kathrin and Peter Pagin, 1999. 'Rules of meaning and practical reasoning'. Synthèse (117): 207-227.

Harman, Gilbert, 1977. 'How to use propositions'. American Philosophical Quarterly (14): $173-176$. 
Jeshion, Robin, 2010. 'Singular thought: acquaintance, semantic instrumentalism, and cognitivism'. In New Essays on Singular Thought, edited by Robin Jeshion, 105-140. Oxford: Oxford University Press.

Jeshion, Robin, 2002. 'Acquiantanceless De Re Belief'. In Meaning and Truth: Investigations in Philosophical Semantics, edited by Joseph Keim Campbell, Michael O.'Rourke \& David Shier, 53-74. New York: Seven Bridges Press.

Hawthorne, John and Manley, David. 2012. The Reference Book. Oxford: Oxford University Press.

Kaplan, David, 2012. 'An Idea of Donnellan'. In The Philosophy of Keith Donnellan, edited by Joseph Almog and Paolo Leonardi, 122-175. Oxford: Oxford University Press.

Kaplan, David, 1989. 'Demonstratives'. In Themes from Kaplan, edited by Joseph Almog, Howard Wettstein and John Perry, 481-563. New York: Oxford University Press.

Kratzer, Angelika, 2002. 'Facts: Particulars or information units?' Linguistics and Philosophy (25)(5-6): 655-670.

Lopes, Domenic Maciver, 2003. 'The aesthetics of photographic transparency'. Mind (112) (447): 434-448.

Maddy, Penelope, 1980. 'Perception and mathematical intuition'. Philosophical Review (89) (2): 163-196.

McGinn, Colin, 1981. 'The Mechanism of Reference'. Synthese (49)(2): 157-186.

Morgan, Daniel, 2015. “The Demonstrative Model of first-person thought”. Philosophical Studies 172 (7): 1795-1811

Nanay, Bence, 2010. 'Transparency and sensorimotor contingencies: Do we see through photographs?' Pacific Phil. Quarterly (91)(4): 463-480.

O’Brien, Lucy. 2007. Self-Knowing Agents. Oxford and New York: Oxford University Press. O’Brien, Lucy, 1995. 'Evans on self-identification'. Noûs (29)(2): 232-247. 
Pagin, Pagin. 1987. Ideas for a theory of rules. (PhD thesis), Department of Philosophy, Stockholm University.

Parsons, Charles, 1980. 'Mathematical Intuition'. Proceedings of the Aristotelian Society (80) (1): $145-168$.

Peacocke, Christopher. 2014. The Mirror of the World. Oxford: Oxford University Press.

Peacocke, Christopher. 2008. Truly Understood. Oxford: Oxford University Press.

Pepp, Jessica, forthcoming. 'What Determines the Reference of Names? What Determines the Objects of Thought?' Erkenntnis (to appear).

Russell, Bertrand, 1910/11. 'Knowledge by Acquaintance and Knowledge by Description'. Proceedings of the Aristotelian Society, New Series (11)(1): 108-128.

Russell, Bertrand, 1905. 'On Denoting'. Mind, New Series (14): 479-493.

Searle, John. 1983. Intentionality: An Essay in the Philosophy of Mind. Cambridge: Cambridge University Press.

Sosa, Ernest, 1970. 'Propositional Attitudes de Dicto and de Re'. Journal of Philosophy (67)(21): 883-896

Sutton, Jonathan, 2001. 'The Contingent A Priori and Implicit Knowledge'. Philosophy and Phenomenological Research (63)(2): 251-277.

Velleman, David, 2008. 'The Gift of Life'. Philosophy and Public Affairs (36): 245-266.

Walton, Kendall, 1997. 'On Pictures and Photographs: Objections Answered'. In Film Theory and Philosophy, edited by Richard Allen and Murray Smith, 60-75. Oxford: Oxford University Press.

Walton, Kendall, 1984. 'Transparent Pictures: On the Nature of Photographic Realism'. Critical Inquiry (18)(1): 67-72. 